\title{
JUSTICIA RESTAURATIVA y procesos restaurativos: La comunidad hace la diferencia*
}

\author{
Por: Diana Britto Ruíz**
}

\section{Resumen}

El documento hace un recorrido de análisis jurídico por la justicia restaurativa en comparación con los procesos restaurativos comunitarios, sus ventajas y desventajas, poniendo en contexto de la realidad nacional la relación entre victima y victimario. Igualmente identifica el hecho violento como evento que se sucede en una relación entre víctima y victimario dentro de un contexto de comunidad, aspecto importante ya que vincula un actor que hasta ahora no se ha tenido en cuenta dentro de la tradición de la justicia colombiana.

\section{Palabras Claves}

Justicia, justicia restaurativa, conflicto, violencia, victima, victimario, conciliación, mediación.

\begin{abstract}
This study compares Restorative Justice with other community-based restorative processes from a legal standpoint highlighting advantages and disadvantages and looking into the relationship between victims and criminals in a community context. This perspective introduces new agents in the Colombian judiciary system.
\end{abstract}

\section{**Perfil}

Diana Britto Ruíz es Master en Estudios Políticos de la Pontificia Universidad Javeriana de Cali y Psicóloga de la Universidad del Valle. Actualmente dirige la Carrera de Ciencia Política de la Pontificia Universidad Javeriana de Cali y coordina la línea de Investigación sobre Justicia Restaurativa en el grupo DEIS.

\section{Key words}

Justice, Restorative Justice, conflict, violence, victim, criminal, conciliation, mediation.

\section{Artículo:}

Recibido, 28 de julio de 2006; aprobado, 28 de Noviembre de 2006

* Ponencia presentada en el II Seminario internacional sobre novilencia, octubre 2005. Bogotá. 
Sucede cotidianamente que cuando se habla $\int$ de justicia se tiende a pensar que ese es un tema exclusivo de abogados, por ello cuando en el año 2001 un grupo de académicos nos acercamos a una experiencia comunitaria en el Distrito de Aguablanca en Cali', nos encontramos con que al no estar directamente involucrado un abogado o abogada era permanentemente puesto en tela de juicio si de lo que hablábamos era de Justicia Restaurativa. Se suma a este clima de incertidumbre el hecho de que para ese momento no existía en el marco jurídico del país una reglamentación que diera piso a experiencias como las que estábamos tratando de analizar, en la que una organización de mujeres de base estaba en el empeño de brindar una opción a jóvenes involucrados en el conflicto de pandillas y que ellas visionariamente denominaron Justicia Restaurativa.

Ahora el marco jurídico existe, la Justicia restaurativa está contenida en el Código de Procedimiento Penal, hay planteados mecanismos para ella en lo que se conocen como justicias alternativas. Me propongo en este texto, desarrollar la idea de que puede existir la justicia restaurativa, desde una perspectiva procedimental jurídica, pero la justicia restaurativa en un sentido más amplio no podrá ser sin el desarrollo de procesos restaurativos, y ellos solamente pueden darse en el seno de las comunidades.

Antes de avanzar considero importante presentar una definición de justicia restaurativa y de sus principios para que esto sirva como marco referencial para el desarrollo de la hipótesis.

\section{¿QUÉ ES JUSTICIA RESTAURATIVA?}

La primera consideración para hablar de la justicia está referida a las funciones que debe cumplir la justicia como tal, castigar, rehabilitar y prevenir la aparición de otros delitos.

Hasta el momento en la mayoría de las sociedades modernas el modelo de justicia que se aplica es el denominado justicia retributiva, es decir, la justicia que establece una relación entre el infractor y la sociedad a través de los organismos del Estado que imponen una sanción, en ese sentido el infractor no llega a sentir los verdaderos alcances de su acción y de qué manera ha dañado a la sociedad o a la víctima. Desde dicha perspectiva es muy poco probable que se cuestione sobre sus acciones y procure evadir o minimizar el castigo, a esto se suma el hecho de que las instituciones de reclusión no alcanzan a lograr el objetivo de rehabilitación, lo que genera que cada vez más los delincuentes se distancien de la comunidad y sean excluidos.

Como una alternativa, la justicia restaurativa plantea que los delitos ocurren en el seno de una comunidad contra miembros de la comunidad y en ese sentido el que se asuma la resolución como una relación entre el delincuente y la víctima con el acompañamiento de la comunidad es un procedimiento que facilita que el proceso resulte más eficaz en la sanción, por cuanto sensibiliza al infractor del dolor y los alcances de sus actos; ante tal sensibilización es muy probable que no reincida en los hechos, y que además restablezca los vínculos con la comunidad. En ese sentido la justicia restaurativa condena el acto delictivo, de ninguna manera es impunidad, mantiene la responsabilidad de los delincuentes, pero busca que se involucren todas las personas afectadas en primer o segundo nivel, y alienta el arrepentimiento del delincuente para que trabaje activamente en la reparación del daño causado para que pueda así lograr recuperar su lugar en la sociedad.

La justicia restaurativa representa un cambio en el paradigma de justicia que hasta hoy conocemos, pues busca introducir un nuevo espíritu a la justicia. Cambia el eje para la dinámica del proceso, que hasta este momento está representado por el protagonismo del delincuente o infractor, la justicia restaurativa da un lugar protagónico a la víctima y busca, desde su perspectiva, la transformación del delito y las

1. La Fundación Paz y Bien es una ONG de base, conformada por mujes que tiene como principal objetivo brindar condiciones de vida dignas a las mujeres empobrecidas y a sus familias. E-mail: pazybien@telesat.com.co 
condiciones que lo propiciaron, pero ello no se logra sin la colaboración del victimario, quien debe salir también beneficiado del proceso.

De manera sintética podemos afirmar que la justicia restaurativa es un modelo de justicia comunitaria, cuyo objetivo último es "equilibrar los intereses de la víctima y de la comunidad con la necesidad de reintegrar al delincuente en la sociedad. Busca ayudar a la recuperación de la víctima y permite que toda las partes con interés en el proceso de justicia participen fructíferamente en ello" ${ }^{2}$

Se trata de un modelo alternativo que busca obtenery mantener una paz justa para la sociedad con base en la verdad a través del diálogo, y que debe, en primer lugar, acercar a las víctimas y a la comunidad, dando a las primeras la posibilidad de trascender su lugar de víctimas para que se conviertan en sujetos dignos, poseedores de derechos y capaces de transformar las situaciones de inequidad que la han puesto en el lugar de víctima. En segundo lugar, acercar al ofensor y la sociedad a través del reconocimiento de sus responsabilidades y de la realización de actos de reparación que le permitan resituarse como persona y como ciudadano(a). $Y$ en tercer lugar, debe acercar a las víctimas y sus victimarios, ya fortalecidas las primeras y comprometidos los segundos, con el acompañamiento de la comunidad que sirve como referente y garante en la transformación de la violencia.

En este sentido, la justicia restaurativa es una justicia que, si bien busca el concurso de los expertos y expertas en el tema jurídico, pone su mayor interés en comprender y transformar las bases que subyacen al delito y la violencia apelando a la creación de un pacto social y de una ética de la convivencia, atiende las personas inmersas en el conflicto, pues reconoce que los conflictos y delitos son entre personas y no la fría interpretación o transgresión de un código o norma, y sobre todo reconoce que en cada conflicto, delito y manifestación de violencia hay una historia, y una serie de elementos del orden estructural y cultural que la hacen un fenómenos complejo.

La justicia restaurativa es un modelo de justicia que aplicado con rigurosidad en cuanto a sus principios llevaría a indagar sobre las bases mismas de la violencia, los conflictos y/o delitos, los cuales según importantes teóricos de la paz como Johan Galtung ${ }^{3}$ tienen diferentes niveles de expresión que es necesario atender para una verdadera resolución; éstos son la violencia física (manifestación evidente, por ejemplo el golpe, la lesión) la violencia estructural (aspectos que están en las bases mismas de la sociedad y que de alguna manera contribuyen a la manifestación física, son las expresiones de la marginalidad) y la violencia cultural (que es el relato que justifica el ejercicio de la fuerza o el lugar de subordinación de unas personas sobre otras).

La justicia restaurativa es una vía para la paz en tanto que es un modelo para abordar el conflicto y la infracción que permite evidenciar los discursos y prácticas que sustentan la violencia, reparar tejido social y hacer frente a algunas manifestaciones de la marginación y la exclusión. Este aspecto es clave por cuanto en el marco de la noviolencia ${ }^{4}$ resulta muy importante alcanzar la paz negativa (no uso de la violencia visible y directa), pero es igualmente importante que no se quede alli y que propicie el abordar otro tipo de elementos presentes en nuestra sociedad como la violencia estructural y la violencia cultural.

En síntesis, podríamos decir que la justicia restaurativa es un modelo de justicia comunitaria que pone todo su énfasis en la dimensión social de los delitos y conflictos. Busca restaurar el lazo social dañado a través de un proceso de reparación y reconciliación entre la víctima y el ofensor, con la mediación de la comunidad. No busca el encierro del infractor sino su rehabilitación a través de la reparación del daño.

2. Friday, P., Ediciones centrales en justicia restaurativa, documento presentado al Instituto Nacional de Ciencias Penales, octubre, 2000.

3. Ver Galtung, J., "Tras la violencia, 3R: Reconstrucción, Reconciliación, Resolución. Afrontando los efectos visibles e invisibles de la guerra y la violencia", Colección red Guernika, Bilbao, 1998.

4. Ver López, M., "Noviolencia y cambio(s) social (es)", actas del I Congreso Hispanoamericano de Educación y Cultura de Paz y Noviolencia, en http://www.ugr.es/eirene/lopezmar.htm. 2002. 
En un sentido radical, la justicia restaurativa procura modificar las relaciones desiguales e injustas que han dado origen a los conflictos y delitos.

Podríamos enumerar los principios de la justicia restaurativa asi ${ }^{5}$ :

1. El crimen, en primera instancia, lesiona las relaciones humanas, en segunda medida es una violación de la ley. Cuando sucede un delito, quienes salen lesionadas son las personas.

2. La justicia restaurativa reconoce que el crimen está mal, pero también reconoce que cuando él ocurre se plantean peligros y oportunidades. Los peligros son los de escalada del conflicto, retaliaciones y nuevos brotes de violencia, y las oportunidades están en la opción de encarar el caso con un sentido de transformación del delito puntual y de todo lo que está en su base, no se aplica con el ánimo del castigo y la sanción.

3. En un delito hay victimas primarias y secundarias. Tendemos a pensar como víctimas solamente en la persona o personas que sufren en primer nivel el daño, o en sus seres más cercanos, pero hay siempre más víctimas, incluso alrededor del ofensor, pues no se debe perder de vista que este enfoque abre el marco de interpretación de los hechos haciendo visible que el impacto del delito y la violencia también afecta a otros miembros de la sociedad.

4. Atiende las necesidades de víctimas, comunidad y ofensores, pues propone una mirada incluyente de todos los que participan de manera directa o indirecta en el hecho delictivo y sus efectos.

5. Se da respuesta al crimen por la vía de la voluntad y la cooperación, con un mínimo de coerción. La justicia restaurativa es una forma alternativa de tratamiento del delito y la violencia a la que deben llegar voluntariamente víctima y ofensor, pues de este consentimiento deriva el compromiso y las posibilidades de que el proceso sea realmente restaurativo.

6. El papel de la comunidad es de cooperación y soporte, pero también de veedora. Esto es muy importante, es la comunidad la que debe acompañar el proceso para que quienes participan en él no salgan más dañados, pero también para que se cumplan las reglas de juego y los acuerdos.

7. No siempre los ofensores querrán cooperar, en esos casos es necesaria la intervención de autoridades externas al proceso. No se puede perder de vista que estamos en un contexto regulado por un sistema jurídico que funciona acorde con una legislación y en el marco constitucional, por ello en ningún caso la justicia restaurativa podrá aislarse de este marco jurídico, por el contrario, debe apoyarse en él.

8. El énfasis no está en la seguridad, sino en la construcción de valores y de una ética de la responsabilidad. Es este el fin último y la principal diferencia con la justicia retributiva; no se busca el castigo, sino la transformación de la injusticia por la vía del diálogo y la responsabilidad.

9. Reconoce que existe rabia y deseo de venganza y por ello el papel de la comunidad es la construcción de una ética y una moral que ayude a contenerlas. Es el reconocimiento de la dimensión humana del delito y las manifestaciones violentas del conflicto.

10. Requiere que la comunidad genere estructuras de seguimiento y supervisión

5. Siguiendo a Mccold, P. y Wachtel T., "En busca de un paradigma: una teoría sobre justicia restaurativa", ponencia presentada en el XIII Congreso Mundial sobre Criminología, en http://iirp.org/library/paradigm span. hłml. 2003. 
de los acuerdos. El primer paso es la construcción de condiciones para que víctima y ofensor puedan dialogar, pero a este paso siguen muchos otros: lograr acuerdos, velar por su cumplimiento y también crear las condiciones para que los actores del proceso logren transformar su lugar en la comunidad.

11. No hay un modelo único de justicia restaurativa. Como ésta es una justicia que atiende los aspectos sociales, psicológicos, jurídicos y culturales presentes en el delito y la violencia, debe ser diseñada para responder a las particularidades de cada grupo social, pero ello no implica desconocer los principios.

\section{LA JUSTICIA RESTAURATIVA EN EL CÓDIGO DE PROCEDIMIENTO PENAL}

Creo importante en este punto hacer la aclaración de que no soy jurista y por lo tanto lo que haré a continuación es una lectura del Código desde el sentido común de una ciudadana, porque considero que un tema tan definitivo para una sociedad debe ser de fácil comprensión para el ciudadano de a pie, ruego entonces me excusen si no uso el lenguaje técnico y agradezco las aclaraciones y correcciones que a bien tengan para hacer los y las juristas que puedan encontrarse en el público.

Veamos ahora cómo se ha diseñado la justicia restaurativa en el Código de procedimiento Penal. En primera instancia el Código define la justicia restaurativa como: "se entenderá por programa de justicia restaurativa todo proceso en el que la víctima y el imputado, acusado o sentenciado participan conjuntamente de forma activa en la resolución de cuestiones derivadas del delito en busca de un resultado restaurativo, con o sin la participación de un facilitador. Se entiende por resultado restaurativo, el acuerdo encaminado a entender las necesidades y responsabilidades individuales y colectivas de las partes y a lograr la reintegración de la víctima y del infractor en la comunidad en busca de la reparación, la restitución y el servicio a la comunidad." Igualmente, define tres mecanismos para la ejecución: la conciliación preprocesal, la mediación y la conciliación en el incidente de reparación integral.

Estas disposiciones también señalan unas reglas particulares que regirán estos procesos:

- Se requiere el consentimiento voluntario de la víctima y del imputado de acudir a un proceso restaurativo.

- Los acuerdos deben contener obligaciones razonables y proporcionadas con el daño ocasionado.

- La participación del imputado, acusado o sentenciado no se utilizará como prueba de admisión de culpabilidad en procedimientos jurídicos posteriores.

- El incumplimiento de un acuerdo no deberá utilizarse como fundamento de manera imparcial y velar porque las partes actúen con mutuo respeto.

\section{Conciliación Preprocesal:}

La conciliación es un mecanismo que se adoptó en todas las áreas del derecho como una forma de descongestionar los despachos judiciales y una manera de apresurar la solución de las controversias entre los interesados, para evitar que los conflictos tuvieran que surtir las instancias judiciales en busca de una solución.

Mediante la conciliación, la víctima y el victimario acuerdan sus voluntades para que de una manera consensuada den solución a la controversia originada con el delito. La conciliación se ceñirá, en lo pertinente, a lo establecido en la ley 640 de 2001.

Según el Código, la conciliación es obligatoria en los delitos querellables y podrá hacerse ante el fiscal, en un centro de conciliación o ante un conciliador o conciliadora reconocido. Si no hay acuerdo, se puede ejercer la acción penal, pudiendo acudir a la mediación durante el proceso. 
Al ser este mecanismo una ruta obligada para el inicio de una acción penal en los casos de delitos querellables, hay dos formas de ser interpretado, la primera, es que si un delito es querellable, es decir, desistible, es porque es un delito menor, por ello es apenas lógico que se busque un arreglo amistoso antes que un pleito prolongado, sin embargo, y esta es la otra perspectiva, vale la pena pensar en cuáles son algunos de los delitos querellables, está por ejemplo todo lo relacionado con violencia familiar, o casos de lesiones personales que causen incapacidad hasta por 60 días, y a juzgar por la celeridad y afán de cifras sobre conciliaciones logradas que rige este estilo de mecanismo alternativo de justicia, vale la pena preguntarse por la calidad de la justicia que se podrá lograr. Quiero dejar en claro que no juzgo la conciliación en sí misma, a la que considero un importante elemento para el tratamiento de los delitos, pero cuando ésta se desarrolla en un ambiente de "conciliatón", mayor cantidad de procesos en el menor tiempo posible, y con el fin último de descongestionar más que de lograr calidad de justicia es importante que nos preguntemos si en el esquema en el que se realiza la conciliación, sin sensibilidad sobre temas como equidad de género y otro tipo de injusticias estructurales y cimentadas en la cultura, será posible llegar a justicia restaurativa en el sentido amplio en el que la planteé anteriormente.

La mediación:

La mediación es un mecanismo por medio del cual un tercero neutral, particular o servidor público designado por el Fiscal General de la Nación o su delegado, trata de permitir el intercambio de opiniones entre la víctima y el ofensor para que confronten sus puntos de vista $y_{\text {, }}$ con su ayuda, logren solucionar el conflicto que les enfrenta.

La persona que hace las veces de mediador o mediadora no administra justicia, es un facilitador o facilitadora neutral para la comunicación entre la víctima y el victimario.

El mediador o mediadora debe acercarse a la víctima y al ofensor a fin de asegurarse de que la mediación sea apropiada para ambos. En particular, intenta asegurase que ambos sean psicológicamente capaces de hacer de la mediación una experiencia constructiva, de que la víctima no se vea aun más perjudicada por el hecho de reunirse con el ofensor, y de que ambos comprendan que su participación es voluntaria. El mediador o mediadora no impone un resultado específico, ni toma ninguna decisión, son las partes quienes acuerdan una solución. En lugar de eso, el rol del mediador o mediadora consiste en facilitar la interacción entre víctima y victimario, procurando que cada uno asuma un rol activo para alcanzar un resultado que sea percibido como justo por ambos.

Con el apoyo del mediador o mediadora, las partes se reúnen a fin de identificar la injusticia, proponer la forma de rectificar el daño, restaurar los perjuicios, y establecer un plan para la restauración y los mecanismos para el seguimiento. Ambas partes presentan su versión de los eventos que condujeron al delito y las circunstancias que lo rodearon. La víctima tiene la posibilidad de hablar acerca de las dimensiones personales de la victimización y pérdida, en tanto que el delincuente tiene la posibilidad de expresar su remordimiento y explicar las circunstancias que rodearon su comportamiento. Luego, las partes se ponen de acuerdo con respecto a la naturaleza y alcance del daño causado por el delito a fin de identificar los actos necesarios para reparar el perjuicio sufrido por la víctima. Las condiciones de la reparación acordadas pueden ser por ejemplo servicios en especie, trabajos para la comunidad, pago económico de daños, petición de disculpas o perdón, entre otros. El acuerdo se recoge en un escrito, junto con los cronogramas de pago, actividades y controles.

El momento en el que se puede solicitar la mediación va desde la formulación de cargos hasta antes del inicio del juicio oral. Aplica para delitos perseguibles de oficio cuyo mínimo de pena no exceda de cinco (5) años de prisión. También se puede solicitar cuando la conciliación preprocesal ha fracasado y cuando víctima y victimario aceptan expresa y voluntariamente someter su caso a una solución de justicia restaurativa.

En los delitos con pena superior a cinco (5) años la mediación es considerada para otorgar 
algunos beneficios durante el trámite, o relacionados con la dosificación de la pena, o el purgamiento de la sanción. El mediador o mediadora debe expedir un informe de los resultados y remitirlos al fiscal o al juez, según el caso, para que los valore y determine sus efectos en el caso.

Los resultados de la mediación son valorados para el ejercicio de la acción penal, la definición del tipo de detención y el establecimiento de la pena al momento de dictarse sentencia. El acuerdo a que lleguen en la mediación tiene efectos vinculantes para la víctima y victimario, es decir, cualquier acuerdo, por ejemplo el simple perdón, lleva a que el afectado o afectada con el delito ya no puede cobrar los periuicios al ofensor ni mediante la acción civil derivada del delito ni abrir el incidente de reparación integral.

Visto de manera general, el mecanismo de la mediación es bastante adecuado para la aplicación de la justicia restaurativa y parece ajustarse a los principios y valores de la misma, nos resta confirmar qué manejo tiene cada uno de los casos para que no sean tratados bajo la lupa del eficientismo y de nuevo se sacrifique calidad por cantidad y rapidez.

En este sentido es importante resaltar experiencias como las de Irlanda del Norte, donde la justicia restaurativa tiene un lugar como justicia alternativa, al igual que en Colombia, pero el procedimiento, una vez las partes deciden tomar esta ruta para el tratamiento de su caso, es celosamente acompañado por personas expertas de la comunidad que inician un proceso lento con cada una de las partes antes de propiciar un encuentro entre ellas, a tal punto que lo describen como un $80 \%$ del esfuerzo dedicado a construir confianza para el encuentro y un $20 \%$ al encuentro en sí mismo, y cada proceso puede durar varios meses, obviamente, esto varía según el caso.

Conciliación en el Incidente de Reparación Integral:

La reparación en el Código no se refiere sólo al pago de los perjuicios causados, comprende también el compromiso de la restitución, devolución o reemplazo de objetos materiales si ello estuviese involucrado en el delito, o a brindar servicios directos a la víctima o a la comunidad.

Es así como el Incidente de Reparación Integral puede iniciarse cuando el ofensor ha sido declarado o declarada culpable y puede ser solicitado por la víctima, el fiscal o el Ministerio Público. Entonces, el juez que ha emitido el fallo abrirá inmediatamente el Incidente de Reparación Integral de los daños causados con la conducta criminal y convocará a audiencia pública en los días siguientes. Esta oportunidad claudica transcurridos 30 días de emitido el fallo.

El Juez puede rechazar la petición de reparación si quien la promueve no es víctima directa o tiene como única pretensión el resarcimiento económico. Si es admitida la propuesta de reparación por parte del delincuente, el juez ofrecerá la posibilidad de una conciliación y si ésta es aceptada dará término al incidente e incorporará el acuerdo a la sentencia.

Abierto el incidente y convocada la conciliación, las partes están obligadas a asistir, quien no comparezca, quedará vinculado a los resultados de la decisión del incidente.

Un aspecto particular que quiero resaltar en este mecanismo, es que incluso si la víctima no estuviere de acuerdo con la propuesta de reparación que realiza el victimario, el juez la puede juzgar adecuada y por lo tanto el victimario tendrá la posibilidad de ejecutar el plan de reparación y recibir los beneficios que de éste derive. En este caso, el administrador de justicia puede juzgar que los intereses de la víctima se ven favorecidos por la propuesta de reparación, incluso aunque ella misma no lo entienda. Quiero señalar en este punto que aunque es loable el propósito, desconocer a la víctima como agente activo en el proceso y en su vida es una nueva forma de victimización.

Estos son los tres mecanismos de justicia restaurativa que señala el Código de Procedimiento Penal, conciliación preprocesal, mediación y conciliación en el incidente de reparación integral, pero es muy importante resaltar otros elementos innovadores incluidos en él y que pueden resultar muy esclarecedores 
acerca de las motivaciones que puede tener un delincuente para que el caso sea tratado por la justicia restaurativa:

\section{Principio de Oportunidad:}

El Estado, por intermedio de la Fiscalía General de la Nación, está obligado a ejercer la acción penal y a realizar la investigación de los hechos que revistan las características de delito, de oficio - que llegue a su conocimiento por medio de denuncia, petición especial, querella o cualquier otro medio, salvo las excepciones contempladas en la Constitución Política y en el Código de Procedimiento Penal. No podrá en consecuencia, suspender, interrumpir ni renunciar a la persecución penal, salvo en los casos que establezca la ley para aplicar el principio de oportunidad regulado dentro del marco del Estado, el cual estará sometido al control de legalidad por parte del juez de control de garantías.

Lo que esto quiere decir es que el Código ha abierto la posibilidad de que en algunos casos el Estado podrá suspender acciones judiciales con el denominado principio de oportunidad y para ello señala 17 tipos de casos en los que él aplica. Para ilustrar este punto se puede citar una situación clásica en la que creo ninguna persona de las aquí presentes tendría duda es una medida aceptable: un padre o madre, que accidentalmente al sacar el carro del parqueadero atropella a su hijo o hija, en este caso un juez podrá decir que ya la persona ha sufrido tanto por el dolor del fatal error y la pérdida - lesión de su hijo, que no aplicará sanción. Pero hay otros casos en los que tal vez la cuestión ya no es tan fácilmente asimilable, y es el caso por ejemplo del juzgamiento de una persona que posea información que ponga en riesgo la seguridad exterior y pueda utilizarla en el marco del proceso.

Solamente como dato interesante, este mecanismo existe en países como México, y según algunos juristas de esa nación, ha servido como plataforma para impunidad y corrupción. Como éste no es asunto de esta ponencia lo dejo alli, y finalizo el punto con la información de que este principio está demandado ante la Corte
Constitucional porque parece ser violatorio de la obligación constitucional que tiene el Estado de investigar y castigar los delitos.

Pero en relación con la justicia restaurativa, el principio de oportunidad se activa cuando se acepta la conciliación en el incidente reparación y por ende el caso pasa a lo que se denomina suspensión del procedimiento a prueba, es decir se suspende la acción legal para dar paso al cumplimiento de las condiciones de reparación pactadas.

\section{Suspensión del Procedimiento a Prueba:}

La suspensión del procedimiento a prueba será solicitada por el imputado al fiscal mediante solicitud oral en la que presenta un plan de reparación del daño y las condiciones que estaría dispuesto a cumplir. El plan podrá consistir en la reparación integral de los daños causados a las víctimas o la reparación simbólica, y en los plazos para su cumplimiento. El fiscal consultará a la víctima y resolverá de inmediato y fijará las condiciones bajo las cuales se suspende el procedimiento, y aprobará o modificará el plan de reparación propuesto por el imputado, ojalá con el beneplácito de la víctima, aunque éste no es una condición. En ningún caso la suspensión podrá ser superior a tres años. Si por alguna razón el caso vuelve a ser reanudado, todo lo que el victimario haya reconocido durante la suspensión del procedimiento no podrá ser tomado en su contra.

Durante la suspensión del procedimiento a prueba el imputado deberá cumplir con una o varias de las siguientes condiciones, según lo estime conveniente el fiscal:

- Residir en un lugar determinado e informar al fiscal cualquier cambio del mismo.

- Participar en programas especiales de tratamiento con el fin de superar problemas de dependencia o drogas o bebidas alcohólicas.

- Prestar servicios a instituciones que se dediquen al trabajo social en favor de la 
comunidad.

- Someterse a un tratamiento médico o psicológico.

- Manifestar públicamente su arrepentimiento por el hecho que se le imputa.

- Observar buena conducta individual, familiar y social.

- Dejar efectivamente las armas y manifestar expresamente su intención de no participar en actos delincuenciales.

- No poseer o portar armas de fuego.

- No conducir vehículos automotores, naves o aeronaves.

- Reparar integralmente a las víctimas, de conformidad con los mecanismos establecidos en la ley.

- Realizar actividades en favor de la recuperación de las víctimas.

- Colaborar activa y efectivamente en el tratamiento psicológico para la recuperación de las víctimas, siempre y cuando medie su consentimiento.

Durante el período de prueba el imputado deberá someterse a la vigilancia que el fiscal determine sin menoscabo de su dignidad, y vencido el período de prueba y verificado el cumplimiento de las condiciones el fiscal ordenará el archivo definitivo del caso valiéndose del principio de oportunidad.

El juez de control de garantías debe efectuar el control de legalidad de la aplicación del principio de oportunidad, dentro de los cinco días siguientes a la determinación de la fiscalía de aplicarlo, siempre que con ésta se extinga la acción penal. Dicho control será obligatorio y automático y se realizará en audiencia especial en la que la víctima y el Ministerio Público podrán controvertir la prueba aducida por la Fiscalía General de la Nación para sustentar la decisión. El juez resolverá de plano y no procederá recurso alguno si las partes implicadas no estuvieren de acuerdo.

\section{LOS PROCESOS RESTAURATIVOS Y LA JUSTICIA RESTAURATIVA}

Hasta el momento he planteado dos grandes cuestiones, de un lado he realizado un presentación de lo que se entiende por justicia restaurativa y sus principios, y por el otro he tratado de presentar la manera como nuestro ordenamiento jurídico le ha dado lugar a su aplicación, es entonces el momento de desarrollar la argumentación en torno a lo expresado en el comienzo, en relación con que la justicia restaurativa según se propone en el marco legal se queda en una cuestión puramente procedimental que no garantiza la restauración, cuando no convoca la comunidad.

En el Gráfico 1, se representa un paralelo entre ambas ideas, la justicia restaurativa y los procesos restaurativos en relación con el papel que juegan los actores del proceso.

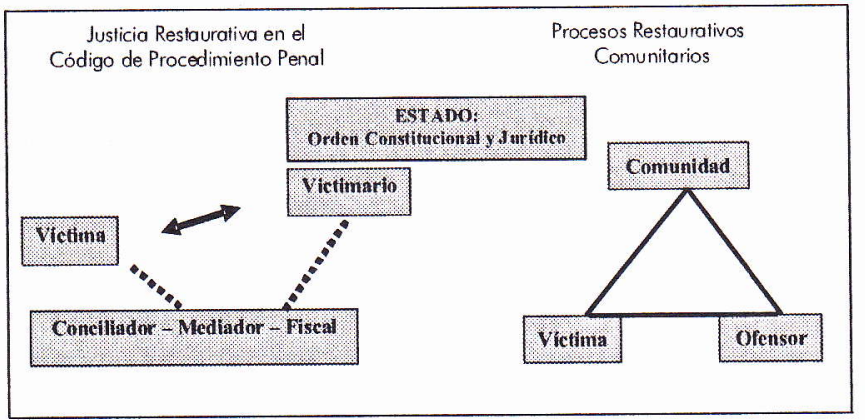

Gráfico 1. Representación de la dinámica de los actores de la justicia restaurativa en el ordenamiento legal y en procesos comunitarios. Diana Britto R. (2005)

Se entiende que la verdadera restauración radica en el hecho de que se logre transformar la dinámica desigual de poder entre víctima y victimario, a partir de que la primera reciba una reparación material y simbólica adecuada que le permita trascender su lugar de sumisión, impotencia e indignidad y el segundo asuma la responsabilidad por sus actos ante la víctima y la sociedad, recibiendo una sanción material y simbólica y comprometiéndose con la realización 
de la reparación de la víctima y la sociedad.

La justicia restaurativa exige un primer arreglo de voluntades, pero se consolidará solamente cuando se activen procesos de restauración que den respuesta al fenómeno del delito en toda su magnitud, es decir, atendiendo a su historia y a las bases culturales y estructurales que subyacen a él.

Comúnmente la justicia restaurativa se representa con un triángulo en el que víctima y ofensor están en equilibrio gracias a la participación de la comunidad, que sirve como garante en el proceso de restauración y que trabaja activamente en la reparación de las relaciones y en la transformación de las bases del delito o manifestaciones violentas del conflicto. Obviamente, la justicia restaurativa en contextos comunitarios no es una justicia al margen del ordenamiento jurídico y constitucional.

En el gráfico, la representación de la Justicia Restaurativa según el Código de Procedimiento Penal muestra una situación de desequilibrio entre víctima y victimario porque es necesario reconocer que precisamente de esa condición de inequidad emerge la violencia y el delito, y muestra a las figuras del conciliador, el fiscal y el mediador vinculadas a ellos a través de líneas punteadas porque, según define el Código, pueden o no acompañar el proceso de arreglo entre ambos, es decir, podría suceder que víctima y victimario se presenten a formalizar una conciliación y ello sería considerado un arreglo restaurativo. A mi modo de ver, ésta es una propuesta que no se ajusta a los principios de la justicia restaurativa, puesto que desconoce las bases del delito y su historia, y sobretodo deja de lado la posibilidad sanadora y de acompañamiento que tiene la comunidad para garantizar que estos fenómenos no sucedan más.

De otra parte, la participación de los mediadores, conciliadores y fiscales es definitiva como puerta de entrada a verdaderos procesos restaurativos, y si bien a los administradores de justicia no les compete ir más allá de la aplicación de ella, generar vínculos con organizaciones que lideran procesos sociales y que puedan dinamizar la restauración con el acompañamiento y apoyo a víctimas y victimarios es imperativo. Pues de no ser así, todo lo planteado en el Código puede quedar en un saludo a la bandera de la restauración, perdiéndose la oportunidad de posibilitar una verdadera revolución en materia de justicia y construir las bases para la paz positiva que tanto reclama nuestro país.

Es necesario aclarar que el elemento que hace la diferencia y complementariedad entre justicia restaurativa y procesos restaurativos es la comunidad, entendida ésta como organizaciones sociales de base con proyectos colectivos y cuyos integrantes cuenten con o reciban la formación para realizar conciliaciones, mediaciones y procesos restaurativos que se enfoquen a crear condiciones para el florecimiento de la paz positiva.

Las organizaciones sociales de base que pueden aportar los procesos restaurativos a la justicia restaurativa son organizaciones que lideran procesos que incluyen lo sociocultural, lo económico y lo político.

a. Procesos Socioculturales: para la construcción de una ética de la convivencia

Todo grupo social activa mecanismos para la regulación de los conflictos, las denominadas formas de regulación social que son la moral, la cultural y la ley ${ }^{6}$. La moral está en los valores y principios que deben ser inculcados en la familia, la cultural en las dinámicas sociales y mecanismos de control social que deben operar para que la convivencia sea posible y la legal en el funcionamiento de los organismos de control del Estado en pro del imperio de la ley bajo el marco de los derechos humanos y la equidad de género.

Es necesario entonces, que los procesos restaurativos estén enfocados a dinamizar un sistema en el que la relación entre los ámbitos

6. Mockus, A., Corzo, J., "Divorcio entre ley, moral y cultura", en http://www.idct.gov.co/descargas/documentos world/cultura ciu/doc rel/Ley Moral Cultura.doc. 2001. 
moral, cultural y legal se convierta en una plataforma para la regulación pacífica de los conflictos y de tratamiento de los delitos. Quiero dejar en claro que basada en la experiencia que hemos venido acompañando en Aguablanca, el funcionamiento de estas formas de regulación social no son una condición para generar procesos restaurativos, todo lo contrario, en una sociedad tan resquebrajada en este sentido, los procesos restaurativos pueden convertirse en el marco para la reflexión y diálogo que afiance una ética de la convivencia.

b.Procesos Económicos: para el desarrollo de una economía solidaria

¿Por qué la restauración debe acompañarse de procesos económicos? Es corriente encontrar en las argumentaciones sobre las causas de la violencia y el delito los factores económicos; si bien es cierto que es un elemento importante, no podemos ser reduccionistas al simplificar éste como la causa en singular. Una forma fácil de rebatir este argumento es mirar que el delito y la violencia aparecen en diferentes contextos económicos y que no todas las personas pobres son violentas ni todas las personas adineradas son pacíficas. Es claro que la violencia emerge por una complejidad de factores, pero también es cierto que lo económico más que una causa puede ser un buen argumento para ella, y que en el caso particular de los jóvenes de pandillas, por ejemplo, sus actuaciones delictivas son sobre todo para la consecución de objetos suntuosos como tenis y ropa de marca. Es necesario entonces, que las comunidades que asuman el compromiso de acompañar procesos de restauración planteen alternativas económicas que les permitan desempeñar un papel protagónico. De nuevo quiero remitirme a la experiencia de la Fundación Paz y Bien en Aguablanca, una comunidad excluida por múltiples razones y claramente marginada económicamente, se les niega hasta el derecho al trabajo por ser residentes de una zona estigmatizada como violenta, por ello trabajan en un proyecto económico con enfoque solidario y perspectiva de género que es una parte importante en el proceso de restauración con víctimas y victimarios.
C. Procesos Políticos: para la participación política y la consolidación de la democracia

Los dos procesos anteriores están íntimamente ligados a un proceso político de empoderamiento para la participación en el marco democrático. Pensarse una ética de la convivencia y un esquema económico alternativo les sitúa en la arena de lo político, en la que su papel no puede ser pasivo ni limitado a participar en comicios en calidad de votantes. Les exige una formación y reflexión permanente en la que son involucrados víctimas y victimarios.

Cada uno de estos procesos son verdaderas epopeyas, sin embargo, son posibles.

\section{CONCLUSIONES}

1. La justicia restaurativa propone un cambio de paradigma en el tratamiento del delito, propone trascender las acciones puramente punitivas para atender de manera integral el delito como fenómeno humano, con historia, raíces y diversas manifestaciones. Es la comprensión de que el delito es apenas la punta del iceberg, y que si bien es importante atender todas las consecuencias inmediatas que conlleva, es necesario emprender acciones de mediano y largo plazo para que se prevenga.

2. En Colombia se ha dado un importante paso para que la justicia restaurativa se implemente, ha sido incluida dentro del Código de Procedimiento Penal, sin embargo, ello no es garantía de que siguiendo las pautas del Código lleguen todos los efectos positivos que este tipo de justicia puede acarrear. El Código abre una puerta a la justicia restaurativa pero no necesariamente compromete la realización de procesos restaurativos en un sentido amplio para la construcción de la paz.

3. Lo que busca en últimas la justicia restaurativa es que víctima, victimario y comunidad salgan fortalecidos $y$ 
transformados del proceso y ello no se logra con la firma de un acuerdo o con actos de contrición solamente, estos dos aspectos son necesarios pero no suficientes para que la restauración se dé.

4. En un país como Colombia, donde la violencia y el delito emergen en todas las esferas de la vida social, no podemos resignarnos con incrementar las estadísticas con cifras de conciliación que no atienden y dan cuenta de las bases de injusticia social, económica, cultural y política que subyacen a ellas. Ese tipo de resultados no pueden ser denominados justicia restaurativa. Rompamos el esquema de la "cantidad de justicia" por el de calidad de la justicia.

5. Finalmente, quiero señalar que si bien los expertos en justicia son los juristas, la justicia es mucho más que una cuestión de procedimientos $y$ en ese sentido todas y todos debemos convertirnos en expertos y expertas en iusticia. No podemos quedarnos cómodamente sentadas y sentados esperando a que los expertos actúen; la justicia que cambie las dinámicas sociales y pueda ser medida con indicadores más integrales, no sólo de la no aparición de la violencia física, sino de justicia social en todo el sentido de la palabra, es una tarea que nos compete como sociedad.

\section{BIBLIOGRAFÍA}

Abello, R., Madariaga, C., "Las redes sociales ¿̇para qué?", en Psicología desde el caribe, N. 3, 1999, pp. 117-135.

Beristain, A. S.J., Criminología y Victimología La alternativa re-creadoras al delito", Ed. Leyer, Colombia, 1998.

Britto, R. Diana. "Justicia restaurativa como emancipación de género", ponencia presentada en el Simposio Internacional Justicia Restaurativa y Paz en Colombia, Universidad Javeriana Cali, Colombia, inédito, 2005.

Britto, D Y Ordóñez, J. "Justicia restaurativa, una forma de integración y transformación social", ponencia presentada en el evento Reconciliación y Derechos Humanos: la noviolencia y la resistencia civil como instrumentos para la reconciliación en Bogotá, diciembre de 2004.

Justicia restaurativa: "Uno mata por amor a la vida", Colombia. Informe de Investigación, inédito, 2003.

Carrillo, A., "Modernidad y nuevos sentidos de lo comunitario", en Educación hoy, N. 29 (141), 2000, pp. 33-48.

Carrillo, A., "Vínculos comunitarios y reconstrucción social", en Revista Colombiana de Educación, N. 3, 2002, pp. 43-66.

Castellanos, G. \& Magaña, A., "Sistematización de la experiencia de las Consejeras de Familia de la Fundación Paz y Bien", Tesis de Grado, Centro de Estudios de Género, Mujer y Sociedad. Universidad del Valle, 2000.

Doucet, lan., (comp.), Buscando la Paz del Mundo. Manual de recursos para la transformación del Conflicto, Colombia, Clara, 1998. 
Elias, Norbert, La civilización de los padres y otros ensayos. Ensayo teórico sobre las relaciones entre establecidos y marginados, Grupo Editorial Norma, Bogotá, 1998.

Fisas, V., Cultura de Paz y gestión de conflictos, España, UNESCO, 1998.

Fitzduff, M., Más allá de la violencia. Procesos de resolución de conflicto en Irlanda del Norte, España, Gernika Gogoratuz, 1998.

Friday, Paul. C. Ediciones Centrales en Justicia Restitutiva, Documento que se presenta al Instituto Nacional de Ciencias Penales, octubre 2000.

Galtung, J., "Teoría del conflicto", en Paz por medios pacíficos: paz y conflicto, desarrollo y civilización, España, Gernika Gogoratuz, 2003.

"Tras la Violencia, 3R: Reconstrucción, Reconciliación, Resolución. Afrontando los efectos visibles e invisibles de la guerra y la violencia", Colección Red Guernika. Bilbao, España, 1998.

García-Pablos, Antonio, Tratado de Criminología, Ed. Tirant Lo Blanch, Valencia, España, 1999.

García, Mauricio. De Sousa Santos, Boaventura, Caleidoscopio de las Justicias en Colombia, Siglo del Hombre Editores, Colombia, 2001.

Emancipación Social y Violencia en Colombia, Ed. Norma, Colombia, 2004

Lederach, J. P., ¿Conflicto y Violencia? i Busquemos Alternativas Creativas!, Colombia, Clara, 1995.

- Construyendo la Paz. Reconciliación Sostenible en sociedades divididas, España, Gernika Gogoratuz, 1998.

LEY 906 de 2004 o Nuevo Código de Procedimiento Penal. Colombia.

López, M., "Noviolencia y cambio(s) social (es)", Actas del I Congreso Hispanoamericano de Educación y Cultura de Paz y Noviolencia. España,
Universidad de Granada, en http:// www.ugr.es/ - eirene/lopezmar.htm.

Martín-Baró, Ignacio, Sistema, Grupo y Poder. Psicología Social desde Centroamérica, UCA. Salvador, 1998.

Madariaga, C. Y Sierra, O., "Redes sociales y pobreza", en Psicología desde el Caribe, N. 5, 2000, pp. 127-155.

Mccold, P. Y Wachtel T., "En Busca de un Paradigma: una teoría sobre Justicia Restaurativa", ponencia presentada en el XIII Congreso Mundial sobre Criminología, del 10 al 15 de agosto de 2003, en Rîo de Janeiro. International Institute for Restorative Practics, en http://iirp.org/library/paradigm_span.html, 2003.

Mockus, A., Corzo, J., "Dos caras de la Convivencia: cumplir acuerdos y normas y no usar ni sufrir violencia", trabajo sobre Indicadores de Convivencia Ciudadana, informe final a Colciencias. Colombia, 2001

, "Divorcio entre ley, moral y cultura", en http://www.idct.gov.co/descargas/documentos word/cultura_ciu/doc_rel/Ley_Moral_Cultura.do c, 2001 .

Muñoz, Édgar; RamíRez, Uriel, "Agentes Externos y Autonomía de las Organizaciones Populares en el Distrito de Aguablanca", tesis, Colombia, 1990.

Muñoz, Édgar. Rotawinsky. William. VANEGAS, Gildardo. ESPINOSA., Rafael. Victimización en Colombia: Un análisis exploratorio del caso de la ciudad de Cali, Cali, 1999, Banco Mundial

Muchinik, E., "Las redes sociales de Apoyo: ¿podemos reconstruir la comunidad?", Revista Argentina de Clínica Psicológica, N. 22, 1993, pp. 174-181.

O'Donell, Guillermo, Contrapuntos. Ensayos escogidos sobre autoritarismo y democratización, Ed. Paidós, Barcelona, 1978. 